\title{
Crystal structure of $\mathrm{Hf}_{6} \mathrm{PtAl}_{2}$ and comparison with HfPtAl
}

\author{
Yuriy VERBOVYTSKY ${ }^{1 *}$, Kazimierz ŁĄTKA ${ }^{2}$ \\ ${ }^{1}$ Ivan Franko National University of Lviv, Kyryla i Mefodiya St. 6, 79005 Lviv, Ukraine \\ ${ }^{2}$ Marian Smoluchowski Institute of Physics, Jagiellonian University, \\ Reymonta 4, 30-059 Kraków, Poland \\ * Corresponding author. E-mail: yuryvv@bigmir.net
}

Received January 30, 2008; accepted September 29, 2008; available on-line March 19, 2009

The $\mathrm{Hf}_{6} \mathbf{P t A l}_{2}$ and HfPtAl compounds have been synthesized by arc-melting followed by heat treatment at $800^{\circ} \mathrm{C}$ for ten days. These intermetallics crystallize with hexagonal symmetry and have the lattice parameters $a=7.9054(3) \AA, c=3.3438(1) \AA$ (space group $P \overline{6} 2 m$ ) for $\mathrm{Hf}_{6} \mathrm{PtAl}_{2}$ and $a=7.09197(8) \AA, c=7.1152(1) \AA$ (space group $P \overline{6} 2 c$ ) for HfPtAl.

\section{Hafnium platinum aluminide / Crystal structure / X-ray powder diffraction}

\section{Introduction}

Some of the Hf- $d$-metal-Al systems show the existence of intermetallic compounds with different superstructures of the $\mathrm{Fe}_{2} \mathrm{P}$ type. Markiv et al. [1,2] found the equiatomic compound $\mathrm{HfNiAl}$ and the ternary compounds $\mathrm{Hf}_{6} \mathrm{MAl}_{2}(M=\mathrm{Fe}, \mathrm{Co}, \mathrm{Ni})$, which crystallize with the $\mathrm{ZrNiAl}$ and $\mathrm{Zr}_{6} \mathrm{CoGa}_{2}$ (anti$\mathrm{K}_{2} \mathrm{UF}_{6}$ ) structure types, respectively. Both structures are ordered variants of the $\mathrm{Fe}_{2} \mathrm{P}$ type (i.e. $\left.\mathrm{Fe}_{3}^{(1)} \mathrm{Fe}_{3}^{(2)} \mathrm{P}_{2}^{(3)} \mathrm{P}_{1}^{(4)}\right): \quad \mathrm{Al}_{3}^{(1)} \mathrm{Zr}_{3}^{(2)} \mathrm{Ni}_{2}^{(3)} \mathrm{Ni}_{1}^{(4)}$ for $\mathrm{ZrNiAl}$ and $\mathrm{Zr}_{3}^{(1)} \mathrm{Zr}_{3}^{(2)} \mathrm{Ga}_{2}^{(3)} \mathrm{Co}_{1}^{(4)}$ for $\mathrm{Zr}_{6} \mathrm{CoGa}_{2}$. In our previous paper [3] we have shown that the related ZrPtAl and HfPtAl compounds belong to the HfRhSn type (i.e. $\mathrm{Hf}_{6}^{(1)} \mathrm{Sn}_{6}^{(2)} \mathrm{Rh}_{4}^{(3)} \mathrm{Rh}_{2}^{(4)}$ ), a superstructure of $\mathrm{Mg}_{2} \mathrm{Ga}$ (i.e. $\mathrm{Mg}_{6}^{(1)} \mathrm{Mg}_{6}^{(2)} \mathrm{Ga}_{4}^{(3)} \mathrm{Ga}_{2}^{(4)}$ ). The latter is a deformed variant of the $\mathrm{ZrNiAl}\left(\mathrm{Fe}_{2} \mathrm{P}\right)$ type [4]. In this paper we report the results of the crystal structure investigation of a new compound, $\mathrm{Hf}_{6} \mathrm{PtAl}_{2}$. For the purpose of comparison we also reinvestigated the structure of the HfPtAl intermetallic, which was synthesized under the same conditions as $\mathrm{Hf}_{6} \mathrm{PtAl}_{2}$.

\section{Experimental details}

Starting materials for the preparation of $\mathrm{Hf}_{6} \mathrm{PtAl}_{2}$ and HfPtAl were hafnium chips, platinum sheets and gallium tear drops, all with purities higher than 99.9 wt.\%. The samples were prepared directly from the elements by arc-melting under an argon atmosphere (with a titanium pellet as a getter) on a water-cooled copper hearth. The products were turned over and re-melted at least three times in order to ensure homogeneity. After arc-melting the mass losses were below 0.5 wt. $\%$. The as-prepared alloys were wrapped in tantalum foil, sealed in evacuated quartz tubes and annealed at $800{ }^{\circ} \mathrm{C}$ for 10 days. After the heat treatment the samples were quenched by submerging the quartz tubes in cold water.

Phase analysis of the alloys was carried out using X-ray powder diffraction (XRD) patterns obtained on a DRON-2.0 diffractometer with $\mathrm{Fe} \mathrm{K}_{\alpha}$-radiation. Another powder diffractometer, HZG-4a with $\mathrm{Cu} \mathrm{K}_{\alpha}$ radiation, was used for the crystal structure determination of the investigated intermetallic compounds. The patterns were recorded in the $\theta / 2 \theta$ mode with the following parameters: $2 \theta$ region $15-145^{\circ}$, step scan $0.05^{\circ}$, counting time per step $20 \mathrm{~s}$. Theoretical powder patterns were calculated using PowderCell [5]. The refinement of the crystal structure was performed by means of the Rietveld method using the program FullProf [6]. A pseudoVoigt profile shape function was used. The background was refined with a $6^{\text {th }}$ order polynomial function.

\section{Results and discussion}

From X-ray phase analyses of samples annealed at $800^{\circ} \mathrm{C}$ a new ternary compound with the composition $\mathrm{Hf}_{6} \mathrm{PtAl}_{2}$ was found in the Hf-rich corner of the $\mathrm{Hf}-\mathrm{Pt}-\mathrm{Al}$ system. Indexing of the XRD pattern showed that this compound is hexagonal with lattice parameters $a=7.9054(3)$ and $c=3.3438(1) \AA$. The analysis of the chemical composition of the alloy and the intensities of the Bragg peaks in the pattern 
Table 1 Crystal data and details of the structural refinement of $\mathrm{HfPtAl}$ and $\mathrm{Hf}_{6} \mathrm{PtAl}_{2}$.

\begin{tabular}{c|c|c}
\hline Compound & $\mathrm{Hf}_{6} \mathrm{PtAl}_{2}$ & HfPtAl \\
Prototype & $\mathrm{Zr}_{6} \mathrm{CoGa}_{2}$ & HfRhSn \\
Space group, Z & $P \overline{6} 2 m(\# 189), 1$ & $P \overline{6} 2 c(\# 190), 6$ \\
Pearson symbol & $h P 9$ & $h P 18$ \\
Unit cell parameters: & & \\
$a, \AA$ & $7.9054(3)$ & $7.09197(8)$ \\
$c, \AA$ & $3.3438(1)$ & $7.1152(1)$ \\
$V, \AA^{3}$ & $180.98(1)$ & $309.921(8)$ \\
$c / a$ or $2 c / a$ & 0.846 & 1.003 \\
Calculated density, g/cm & 12.111 & 12.877 \\
Reliability factors: & & \\
$R_{B}$ & 0.0472 & 0.0654 \\
$R_{F}$ & 0.0296 & 0.0459 \\
$R_{p}$ & 0.0194 & 0.0228 \\
$R_{w p}$ & 0.0248 & 0.0320 \\
Goodness of fit & 1.17 & 1.71 \\
\hline
\end{tabular}

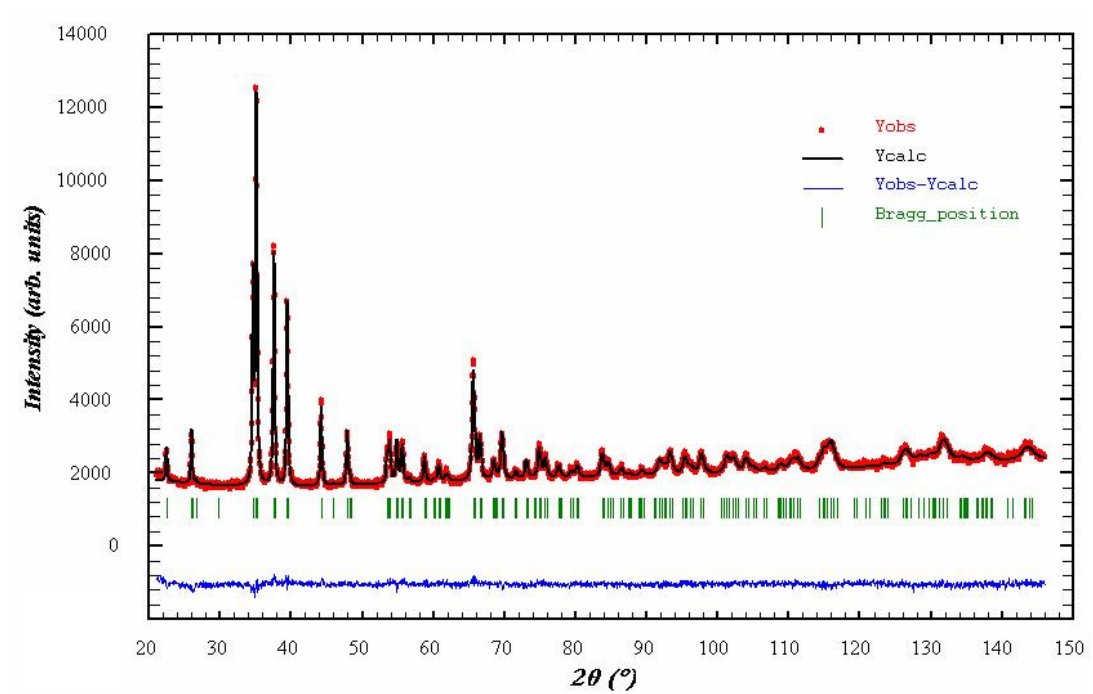

(a)

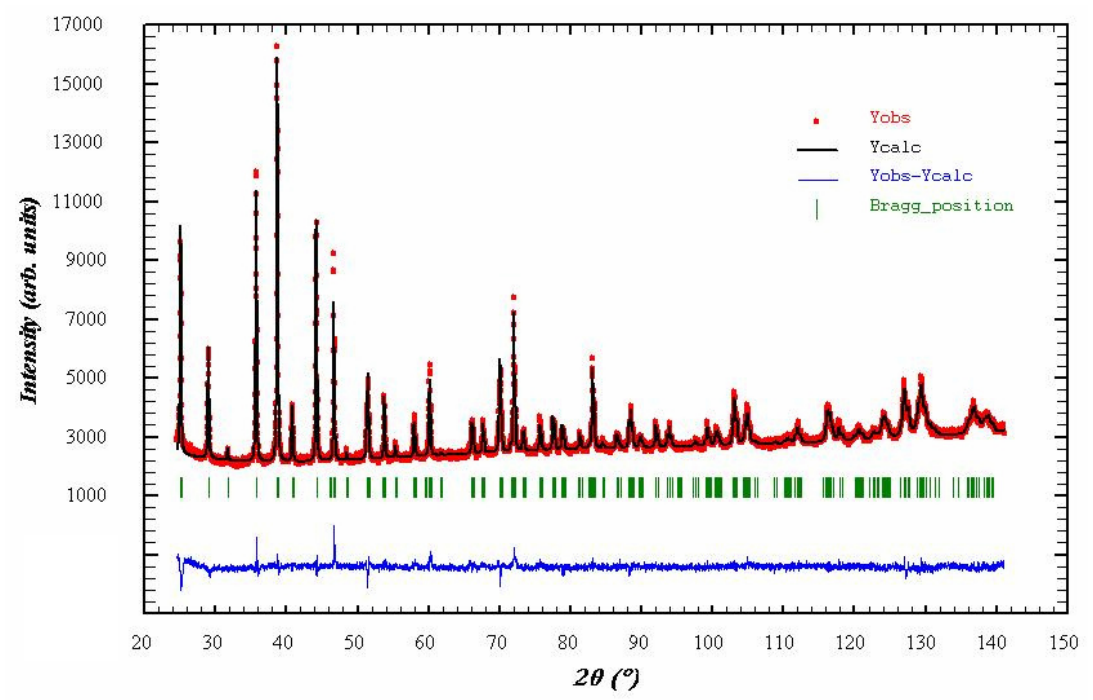

(b)

Fig. 1 Results of the Rietveld profile refinement of the X-ray diffraction data for the ternary compounds $\mathrm{Hf}_{6} \mathrm{PtAl}_{2}$ (a) and HfPtAl (b). Experimental data are represented by dots, calculated profiles by a red line and the difference between observed and calculated intensities as a blue line at the bottom. Vertical bars represent calculated positions of the Bragg peaks. 
indicated the $\mathrm{Zr}_{6} \mathrm{CoGa}_{2}$ structure type. A consecutive Rietveld refinement confirmed this finding. We also reinvestigated the crystal structure of the $\mathrm{HfPtAl}$ compound. For samples quenched either from $600^{\circ} \mathrm{C}$ or $800^{\circ} \mathrm{C}$, a $\mathrm{HfRhSn}$-type structure was found. Its lattice parameters agreed with those published earlier [3]. Crystallographic data and final reliability factors of the structure refinements for $\mathrm{Hf}_{6} \mathrm{PtAl}_{2}$ and $\mathrm{HfPtAl}$ are listed in Table 1. The resulting atomic coordinates and displacement parameters are presented in Table 2. Results of the Rietveld profile refinement of the above mentioned compounds are shown in Fig. 1.

Unit cells and arrangements of trigonal prisms in $\mathrm{Hf}_{6} \mathrm{PtAl}_{2}$ and HfPtAl are presented in Fig. 2. In the structure of $\mathrm{Hf}_{6} \mathrm{PtAl}_{2}$, the platinum and aluminium atoms are located at the centers of undistorted trigonal prisms formed only by hafnium atoms, while in the structure of HfPtAl the platinum atoms are located in two kinds of trigonal prism, i.e. in undeformed prisms built by $\mathrm{Al}$ atoms and slightly distorted prisms composed of Hf atoms.

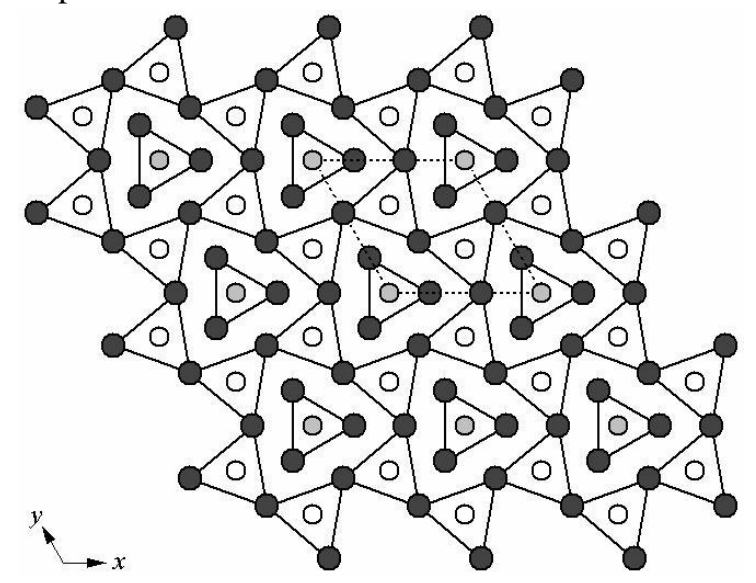

(a)

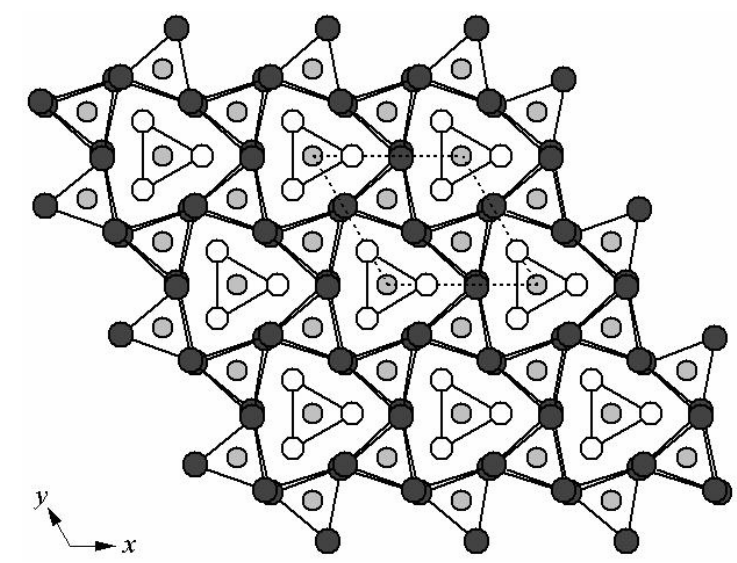

(b)

Fig. 2 Projections of the structures of $\mathrm{Hf}_{6} \mathrm{PtAl}_{2}$ (a) and HfPtAl (b) on the $x y$ plane. Black circles indicate Hf atoms, grey filled circles are $\mathrm{Pt}$ atoms, and $\mathrm{Al}$ atoms are represented by white circles. The unit cells are shown using dotted lines.

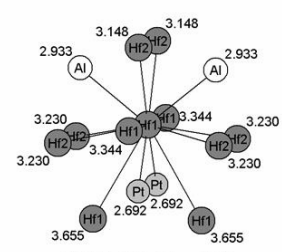

[Hfl $\mathrm{Hf}_{10} \mathrm{Pt}_{2} \mathrm{Al}_{2}$ ]
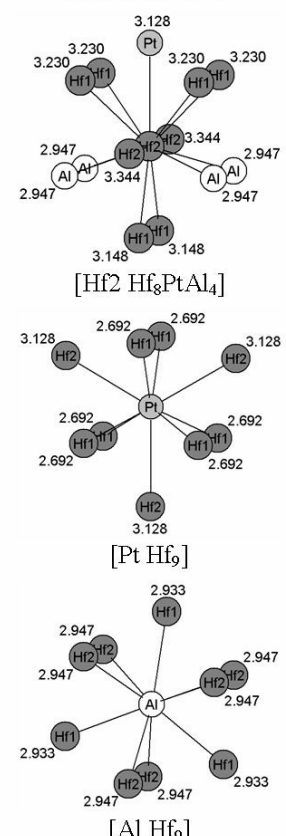

(a)

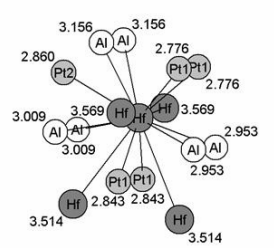

[ $\mathrm{Hf} \mathrm{Hf}_{4} \mathrm{Pt}_{5} \mathrm{Al}_{6}$ ]

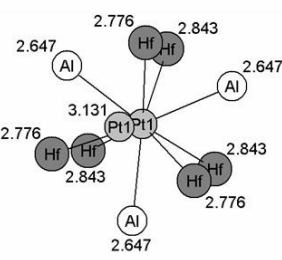

$\left[\mathrm{Ptl} \mathrm{Hf}_{6} \mathrm{PtAl}_{3}\right]$

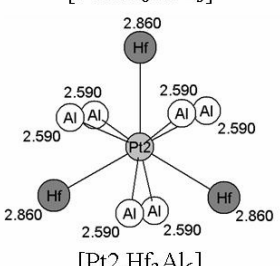

$\left[\mathrm{Pt} 2 \mathrm{Hf}_{3} \mathrm{Al}_{6}\right]$

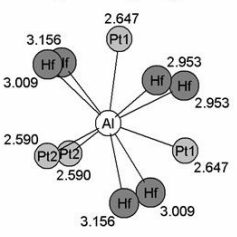

$\left[\mathrm{Al} \mathrm{Hf} \mathrm{Pt}_{6}\right]$

(b)
Fig. 3 Nearest-neighbor environments in the structures of $\mathrm{Hf}_{6} \mathrm{PtAl}_{2}$ (a) and $\mathrm{HfPtAl}$ (b). Coordination polyhedra of the central atoms are indicated. Interatomic distances are shown in $\AA$.

Atom coordinations and interatomic distances are presented in Fig. 3. The shortest Hf-Hf contacts occur in the structure of $\mathrm{Hf}_{6} \mathrm{PtAl}_{2}$, being equal to $3.148 \AA$, which is smaller than the shortest $\mathrm{Hf}-\mathrm{Hf}$ atomic distance $(3.18 \AA)$ in hafnium metal [7]. In the structure of HfPtAl the shortest Hf-Hf contact is much greater and reaches $3.514 \AA$. The shortest Hf-Pt and Hf-Al distances are slightly smaller than the sum of $r_{\mathrm{Hf}}$ and $\mathrm{r}_{\mathrm{Pt}}\left(\mathrm{r}_{\mathrm{Al}}\right): d_{\mathrm{Hf}-\mathrm{Pt}}=2.692 \AA$ and $\mathrm{d}_{\mathrm{Hf}-\mathrm{Al}}=2.933 \AA$ for $\mathrm{Hf}_{6} \mathrm{PtAl}_{2}, d_{\mathrm{Hf}-\mathrm{Pt}}=2.776 \AA$ and $\mathrm{d}_{\mathrm{Hf}-\mathrm{Al}}=2.953 \AA$ for HfPtAl, respectively. For comparison, $r_{H f}+r_{P t}=$ $2.97 \AA$ and $\mathrm{r}_{\mathrm{Hf}}+\mathrm{r}_{\mathrm{Al}}=3.02 \AA$ using values from [7]. The Pt-Pt bonds are longer than the distances in $c c p$ platinum. Contacts between $\mathrm{Pt}$ and $\mathrm{Al}$ are found only in the structure of HfPtAl $\left(\mathrm{d}_{\mathrm{Pt}-\mathrm{Al}}=2.590 \AA\right)$, and the distances are shorter than the sum of $r_{P t}$ and $r_{A l}$, according the data from [7].

To conclude, considering the results of this work and earlier published papers [1-3], six ternary compounds with $\mathrm{Zr}_{6} \mathrm{CoGa}_{2}$ and $\mathrm{ZrNiAl}$ (or $\mathrm{HfRhSn}$ ) structure types have been found in the $\mathrm{Hf}-\{\mathrm{Fe}, \mathrm{Co}, \mathrm{Ni}$, $\mathrm{Pt}\}-\mathrm{Al}$ systems. Their structures are closely related 
Table 2 Atomic coordinates and isotropic displacement parameters for $\mathrm{HfPtAl}$ and $\mathrm{Hf}_{6} \mathrm{PtAl}_{2}$.

\begin{tabular}{|c|c|c|c|c|c|}
\hline Atom & Site & $x$ & $y$ & $z$ & $B_{\text {iso }}, \AA^{2}$ \\
\hline \multicolumn{6}{|l|}{$\mathrm{Hf}_{6} \mathrm{PtAl}_{2}$} \\
\hline Hf1 & $3 g$ & $0.2669(2)$ & 0 & $1 / 2$ & $1.00(5)$ \\
\hline Hf1 & $3 f$ & $0.6043(2)$ & 0 & 0 & $1.10(5)$ \\
\hline $\mathrm{Pt}$ & $1 a$ & 0 & 0 & 0 & $0.5(2)$ \\
\hline $\mathrm{Al}$ & $2 d$ & $1 / 3$ & $2 / 3$ & $1 / 2$ & $1.15(6)$ \\
\hline \multicolumn{6}{|l|}{ HfPtAl } \\
\hline Hf & $6 h$ & $0.4141(3)$ & $0.3914(3)$ & $1 / 4$ & $0.41(3)$ \\
\hline Pt1 & $4 f$ & $1 / 3$ & $2 / 3$ & $0.0300(3)$ & $0.71(3)$ \\
\hline $\mathrm{Pt} 2$ & $2 b$ & 0 & 0 & $1 / 4$ & $0.58(5)$ \\
\hline $\mathrm{Al}$ & $6 g$ & $0.265(1)$ & 0 & 0 & $0.6(2)$ \\
\hline
\end{tabular}

and can be obtained from the hexagonal $\mathrm{AlB}_{2}$ type of structure $[4,8]$.

\section{References}

[1] V.Ya. Markiv, P.I. Kripyakevich, $R\left(X^{\prime}, X^{\prime \prime}\right)_{2}$ compounds in systems with $R=T i, Z r, H f ; X^{\prime}=$ $\mathrm{Fe}, \mathrm{Co}, \mathrm{Ni}, \mathrm{Cu} ; \mathrm{X}^{\prime \prime}=\mathrm{Al}, \mathrm{Ga}$; and their crystal structures, Kristallografiya 11(6) (1966) 859865.

[2] V.Ya. Markiv, V.V. Burnashova, New ternary compounds in the systems $\{\mathrm{Sc}, \mathrm{Ti}, \mathrm{Zr}, \mathrm{Hf}\}-\{\mathrm{V}, \mathrm{Cr}$, $\mathrm{Mn}, \mathrm{Fe}, \mathrm{Co}, \mathrm{Ni}, \mathrm{Co}\}-\{\mathrm{Al}, \mathrm{Ga}\}$, Dopov. Akad. Nauk Ukr. RSR, Ser. A (5) (1969) 463-464 (in Ukrainian).

[3] Yu. Verbovytsky, K. Łatka, The crystal structures of the equiatomic $T T^{\prime} X$ compounds $\left(T=T i, Z r, H f ; T^{\prime}=A u, P t, P d ; X=A l, G a\right)$, J. Alloys Compd. 431 (2007) 130-135.
[4] E. Parthé, L. Gelato, B. Chabot, M. Penzo, K. Cenzual, R. Gladyshevskii, TYPIX, Standardized Data and Crystal Chemical Characterization of Inorganic Structure Types, Springer-Verlag, Berlin, 1994.

[5] W. Kraus, G. Nolge, PowderCell for Windows, Version 2.3, Federal Institute for Materials Research and Testing, Berlin, 1999.

[6] J. Rodriguez-Carvajal, T. Roisnel, FullProf.98 and WinPLOTR: New Windows 95/NT Applications for Diffraction Commission for Powder Diffraction, International Union for Crystallography, Newsletter No. 20 (MayAugust) 1998.

[7] G.B. Bokiy, Kristallokhimiya (Crystal Chemistry), Nauka, Moscow, 1971, 400 p. (in Russian).

[8] R. Pöttgen, R.-D. Hoffmann, $\mathrm{AlB}_{2}$ related intermetallic compounds - A comprehensive view based on group-subgroup relations, Z. Kristallogr. 216 (2001) 127-145. 